\title{
Research on the Application of Digital Multimedia Technology in the Teaching of Film and Television Media in Higher Vocational Education
}

\author{
Liu Yuling \\ Chongqing College of Electronic Engineering, Chongqing, China,401331
}

\begin{abstract}
Keywords: Application, Digital Multimedia Technology, Teaching of Film and Television Media, Higher
\end{abstract} Vocational Education.

\begin{abstract}
With the rapid development and popularization of computer technology, multimedia technology has been widely used in various fields, especially in higher vocational colleges in the application of teaching and it is more and more popular. Multimedia as a supplementary teaching tools, graphic coexistence, vocal effects and so on, it completely break the traditional single teaching methods, a wide range of teaching methods make teaching difficult problems simplistic, solve the traditional difficult teaching problems. This paper discusses the importance of multimedia technology in the teaching of film and television media in higher vocational colleges, and discusses the application of multimedia technology in the teaching of film and television media in higher vocational colleges. This paper discusses the importance of multimedia technology in the teaching of film and television media in higher vocational colleges.
\end{abstract}

\section{Introduction}

Multimedia is a comprehensive high-tech that integrates communication technology and computer with digital technology, which can store, process and transmit various kinds of media information such as text, sound, picture, image and video. As early as the 20th century, 80 years, by the United States Apple Computer set up a multimedia laboratory, through computer technology with a variety of information media technology, to the 20th century, 90 years, multimedia as a new technology used in various fields, especially in the field of education because of its pictures, sound effects, animation, video and other effects, teaching content will be effectively combined play in the screen, for the majority of teachers and students brought a fresh, rich teaching methods to stimulate the enthusiasm of students to learn, so that teaching activities have undergone tremendous changes, students in the relaxed and pleasant environment to learn, thereby improving the quality of teaching.

\section{The Existing Problems of Multimedia in the Vocational Film and Television Media Teaching}

The Over-Reliance on Multimedia. Multimedia teaching is only an auxiliary teaching means and the current technology cannot replace the traditional teaching methods. But some teachers understand the multimedia technology as a substitute for the traditional lesson preparation, in order to save trouble, most of the lectures when the boring script, it is difficult to attract the attention of students, so that both a waste of time and waste of resources to achieve satisfactory teaching results, and some teachers because of their own computer multimedia knowledge and skills of the weak, but also want to rely on multimedia teaching, when the teaching of multimedia failure, they will be on the podium to show the helpless. Hard to cope with, and no good solution, they just will teach the contents stored in the computer, the use of machinery, but did not carefully prepare the lesson, including the preparation of computer media problems, not really the contents of the class stored in the brain. Once left multimedia or multimedia courseware abnormal phenomenon, teaching work was disrupted or unable to proceed, so that teaching into a passive state.

Low Level of Multimedia Applications, Lack of Research. Multimedia technology has been widely used in teaching for several years, and its rich audio-visual form to win the majority of 
teachers and students of love, but because of some of the technical level of coaches, teaching courseware in the production and classroom teaching methods there are some shortcomings, they only part of the textbooks in the text of the mechanical paste in the multimedia courseware, ignoring the focus of teaching. It is difficult and even do not consider the coherence of teaching content and logical reasoning, blindly pursue the courtesy of the surface of the courtesy, the teacher's teaching methods and methods have not fundamentally changed, so colorful. Overwhelming courseware, not only distract the attention of students, but also deprived of their free imagination of space and power, due to the low level of courseware production, and no research with courseware case teaching methods, it is difficult to highlight the focus of the course content and knowledge, so that the teacher's knowledge and students to accept the knowledge greatly blocked.

It Ignored the Role of Blackboard. As a result of the emergence of multimedia technology, many teachers rely too much on computer multimedia, a class to take a laptop to the classroom, which more and more ignore the blackboard plus chalk mode of traditional teaching mode, but the multimedia restrictions and frequent changes in the courseware Picture, if the blackboard is only a brief, affecting the overall effect of blackboard, indirectly affect the overall awareness of students, and traditional blackboard can be presented to the students to consolidate the knowledge of "integrity" normative.

\section{The Advantages of Multimedia Technology in the Teaching of Film and Television Media in Higher Vocational Education}

Interactive, Scientific and Effective. In the classroom teaching process, the use of multimedia technology, visualization, visualization of the characteristics of a large number of teaching knowledge content, through flexible methods and image of the video, animation can be made into interactive courseware, feedback for the students and the degree of acceptance, as well as the difficulties in teaching, focusing on many times to reproduce to everyone to deepen the understanding and impression of students, while giving full play to the leading role of teachers, so the application of multimedia teaching traditional teaching methods and modern teaching methods combine, give full play to their respective teaching functions, in order to improve the quality of teaching.

The Multimedia Can Break Through Time and Space Constraints. In the macro-natural phenomenon, things are in the continuous development of change and upgrading. The use of computer multimedia technology courseware can provide students with vivid "rich content and visual impact of strong materials, so that the abstract things specific way to overcome the students by the constraints of space and time conditions, thereby enhancing the teaching effect.

Flexible Diversity. Multimedia teaching is a popular modern teaching means, not only can provide students with intuitive, specific and vivid teaching content, while teachers can according to their own work experience, and in courseware design, emotional communication, mood atmosphere, etc. to join their own teaching style to increase the fun to attract students to learn attention, in the teacher's guidance to the whole body into the study, through the situation enlightenment, so as to stimulate students curiosity and curiosity, which can do a lot to avoid teaching monotonous issues that help students develop the ability to analyze and solve problems.

\section{The Design of Multimedia Courseware}

According to the work of the Ministry of Education, this year is an important way to improve the quality of teaching and improve the quality of teaching is to give full play to teachers and students in all aspects of individual positive factors, to mobilize the subjective initiative, with multimedia courseware technology, work hard, which courseware design is particularly important, the specific process is as follows

Reasonable and Accurate Topics. According to the content of teaching content is accurate multimedia courseware design to do the first thing to do, or less effective, the design and production 
of courseware is designed to improve the quality of teaching, so before the courseware design, design producers to seriously study syllabus, careful analysis of the relationship between teaching content and courseware, analysis of teaching focus. Difficulties and knowledge points, demonstrate whether the course content can use courseware, if the use of multimedia teaching courseware can be achieved than no courseware better teaching effect.

Design Flow. Everything has its regularity and specific internal relations, multimedia courseware design process is the production of multimedia courseware is an important part of the design of good and bad courseware quality plays a decisive role, so I think the first design of the subject and teaching focus. Second, according to each unit of each contents in the whole to determine the basic way of media presentation.

Scripting. Scripting is the reflection of the designer's teaching ideas, and whether the writing clearly determines the purpose of teaching. Whether the characters can be successfully completed, therefore, teachers in the preparation of the script first of all to the syllabus and teaching objects have a deeper understanding, and the teaching content system is divided into several units, and then, then each large unit to show the content is more detailed divided into a number of courseware display page, the contents of the page can be graphic. Audio video or animation and other components, and finally is based on the link between the various units, integrated into a complete courseware.

The Selection of Courseware Platform. Multimedia technology teaching platform is a complete set. Rigorous service in education and teaching activities of the application software products and related documents, in the courseware production, that is, in the production platform selection, according to the teaching needs to choose suitable function software. Courseware design should be combined with the actual, easy to understand, courseware design time to meet the teaching time, courseware is often used in reciprocating, so to interactively, according to the teaching content and software characteristics to be selected.

\section{The Application of Multimedia Technology in the Teaching of Film and Television Media in Higher Vocational Education}

It is the information explosion era, the same amount of information into the sea impact of people's optic nerve, in the reform into the crucial stage, the multimedia courseware on social culture, economic and political construction has played a pivotal role, the same, the entire multimedia education in the dynamic process have played an irreplaceable role, the use of multimedia teaching can overcome the shortcomings of traditional teaching, received a better teaching effect.

Turn the abstract into a vivid and intuitive classroom presentation. According to the law of education, teachers should use a variety of means to carry out teaching activities, in order to greatly improve the quality of teaching, in order to achieve the ultimate goal of education and teaching, teachers must be in accordance with the requirements of the syllabus, preparation process will be possible in the teaching of the contents of the material and examples, etc. made in advance to include text, pictures, animation, multimedia courseware, the previous need to imagine the dynamic process of visual presentation to the students in order to facilitate students to master and accept, Enhance the real feelings of students, at the same time, because multimedia technology can give people a sense of sensory intuition, so that teachers from the abstract time and effort to explain the freed, with multimedia teachers can teach knowledge and develop students on the other hand, Students' innovative thinking sparks, enhance the intelligence, in the internal to stimulate students to participate in and take the initiative to participate in learning desire to effectively improve the learning efficiency and improve the overall quality of students.

Enhance the authenticity of the simulation teaching. Some vocational colleges due to the existence of certain deficiencies, under certain conditions in order to improve the quality of teaching, we may wish to use simulation teaching. This teaching method refers to the use of multimedia simulation technology, to reproduce some of the actual or difficult to experience things to students to see the teaching activities. This kind of teaching means to make students have immersive, thus increasing the appeal, enhance the teaching effect, improve the teaching level. 
In order to achieve a harmonious society, the industry are fully play the social attributes of people, to the development of local political, economic, cultural and educational. Education due to multimedia technology and teaching courseware of their own advantages, teachers should be based on the actual study of students and true level, the implementation of education and teaching. College students also according to their own actual situation to choose their own multimedia courseware for personal learning greatly enhance and cultivate the autonomy of students. Students can also use the network to share resources for collaborative learning or through the network to ask the teacher, which greatly changed the way students previously accepted the passive way to improve the initiative and targeted students to learn.

\section{Conclusions}

To sum up, the rational use of multimedia technology in teaching is the requirement of teachers in the times. In the actual teaching, the majority of teachers are to use the auxiliary means, and some teachers will combine modern technology and traditional technology to achieve complementary advantages and improve the quality of teaching. It can be seen that the proper use of multimedia technology reflects the improvement of teachers' cultural quality. We can foresee the future of education, multimedia technology development space is still large, will face many problems. But as long as we open their minds, through innovative exploration, multimedia technology will play a greater role in education and teaching, so that information and modernization can be achieved in the teaching of the final.

\section{References}

[1] Wang Chongwen, Ding Gangyi, Yan Dayuan, Chen Lingqi. Exploration and Practice of Digital Media Technology Experimental Teaching Demonstration Center Construction[J]. Experimental Technology and Management 2012 (04)

[2] Dong Xin. Exploration of Innovative Talents Training and Experimental Teaching Reform[J]. Experimental Technology and Management. 2011 (09)

[3] Wang Yue. Discussion on the application of multimedia technology in vocational English teaching[J]. Science and Technology Outlook. 2014 (16)

[4] Zhang Xuelian. Talking about the application of information technology in classroom teaching[J]. Electronic World. 2014 (14)

[5] Feng Dan. Multimedia in the application of tourism teaching[J]. Northern trade. 2013 (06) 